PREPARED FOR THE U.S. DEPARTMENT OF ENERGY, UNDER CONTRACT DE-AC02-76CH03073

PPPL-3834

PPPL-3834

UC-70

\author{
Gyrokinetic Calculations \\ of Microturbulence and Transport
}

by

M.H. Redi, W. Dorland, R. Bell, P. Bonoli, C. Bourdelle, J. Candy,

D. Ernst, C. Fiore, D. Gates, G. Hammett, K. Hill, S. Kaye,

B. LeBlanc, J. Menard, D. Mikkelsen, G. Rewoldt,

J. Rice, R. Waltz, and S. Wukitch

July 2003

MV|

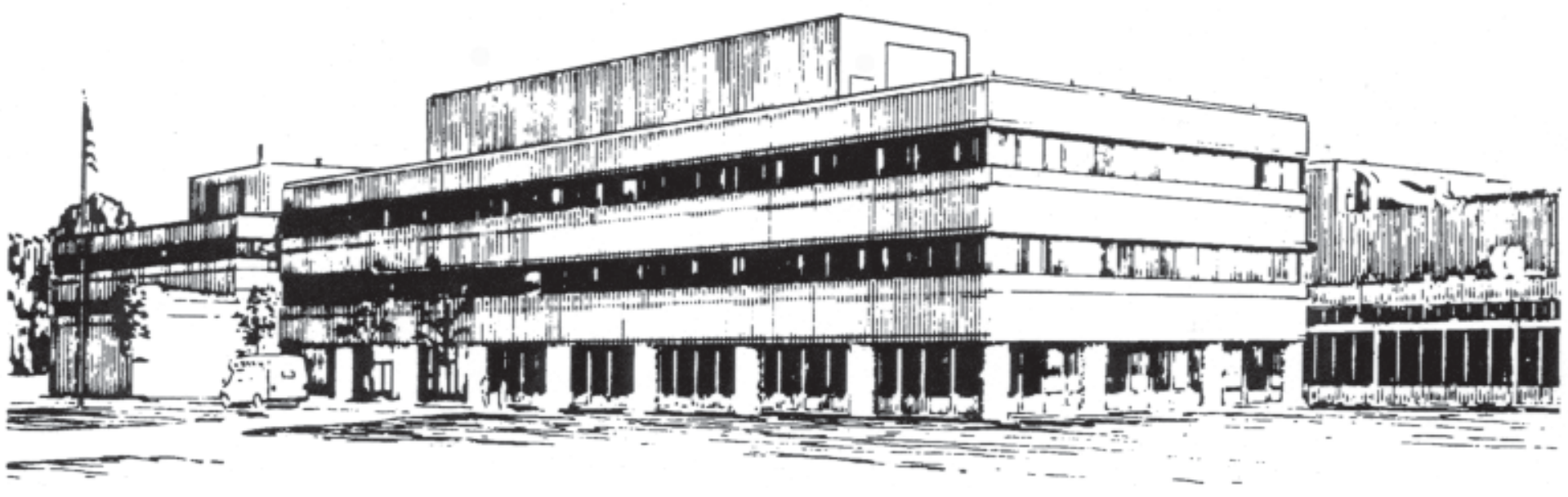

PRINCETON PLASMA PHYSICS LABORATORY PRINCETON UNIVERSITY, PRINCETON, NEW JERSEY 


\section{PPPL Reports Disclaimer}

This report was prepared as an account of work sponsored by an agency of the United States Government. Neither the United States Government nor any agency thereof, nor any of their employees, makes any warranty, express or implied, or assumes any legal liability or responsibility for the accuracy, completeness, or usefulness of any information, apparatus, product, or process disclosed, or represents that its use would not infringe privately owned rights. Reference herein to any specific commercial product, process, or service by trade name, trademark, manufacturer, or otherwise, does not necessarily constitute or imply its endorsement, recommendation, or favoring by the United States Government or any agency thereof. The views and opinions of authors expressed herein do not necessarily state or reflect those of the United States Government or any agency thereof.

\section{Availability}

This report is posted on the U.S. Department of Energy's Princeton Plasma Physics Laboratory Publications and Reports web site in Fiscal Year 2003. The home page for PPPL Reports and Publications is: http://www.pppl.gov/pub_report/

DOE and DOE Contractors can obtain copies of this report from:

U.S. Department of Energy

Office of Scientific and Technical Information

DOE Technical Information Services (DTIS)

P.O. Box 62

Oak Ridge, TN 37831

Telephone: (865) 576-8401

Fax: (865) 576-5728

Email: reports@adonis.osti.gov

This report is available to the general public from:

National Technical Information Service

U.S. Department of Commerce

5285 Port Royal Road

Springfield, VA 22161

Telephone: $1-800-553-6847$ or

(703) $605-6000$

Fax: (703) 321-8547

Internet: http://www.ntis.gov/ordering.htm 


\title{
Gyrokinetic Calculations of Microturbulence and Transport for NSTX and Alcator-CMOD H-modes
}

\author{
M. H. Redi ${ }^{\mathrm{a}}$, W. Dorland ${ }^{\mathrm{b}}$, R. Bell ${ }^{\mathrm{a}}$, P. Bonoli ${ }^{\mathrm{c}}$, C. Bourdelle ${ }^{\mathrm{d}}, \mathrm{J}_{\text {. Candy }}^{\mathrm{e}}$,

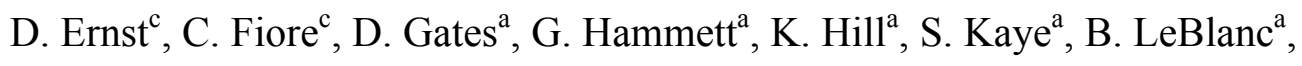

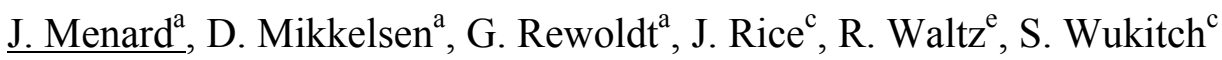 \\ ${ }^{a}$ Princeton Plasma Physics Laboratory, Princeton, NJ 08540, USA \\ ${ }^{b}$ Institute for Plasma Research, U. MD, College Park, MD 20742, USA \\ ${ }^{c}$ Plasma Science and Fusion Center, MIT, Cambridge, MA 02139, USA \\ ${ }^{d}$ Association Euratom-CEA, Cadarache, 13108 St-Paul-lez-Durance, France \\ ${ }^{e}$ General Atomics, San Diego, CA 92186
}

\section{Introduction}

Recent H-mode experiments on NSTX and experiments on Alcator-CMOD which also exhibit internal transport barriers (ITB), have been examined with gyrokinetic simulations with the GS2[1,2] and GYRO[3] codes to identify the underlying key plasma parameters for control of plasma performance and ultimately, the successful operation of future reactors such as ITER. On NSTX the H-mode is characterized by remarkably good ion confinement and electron temperature profiles highly resilient in time[4]. On CMOD, an ITB with a very steep electron density profile[5] develops following off-axis RF heating and establishment of H-mode. Both experiments exhibit ion thermal confinement at the neoclassical level. Electron confinement is also good in the CMOD core.

\section{NSTX Gyrokinetic Simulations}

Linear calculations for NSTX were intended to characterize the microturbulence underlying resilient electron temperature profiles[6]. The initial simulations, at $r / a=0.25$, 0.65 and 0.8 , are fully electromagnetic, follow electrons and three ion species, with the complete electron response. There are no strong ITG or ETG instabilities in the core at $r / a=0.25$ (Fig. 1) where reversed magnetic shear is calculated by EFIT, based on magnetic measurements. A new microinstability is found at $r / a=0.65$ : a microtearing mode (Fig. 2). It is characterized by an odd parity electrostatic eigenfunction rotating in the electron diamagnetic direction, with a broad dispersion spectrum $0.3<k_{\square} \square_{i}<3$. The eigenfunction of $\square B_{\square}$ has even parity and may cause high anomalous electron thermal losses[7]. At $r / a=0.8$ GS2 was used to examine the role of critical temperature gradients and the nearness to marginal stability, usually thought responsible for stiff temperature profiles. The proximity to marginal stability was investigated by scaling the observed, normalized temperature 
gradients, without self-consistently recalculating plasma equilibria. At this radius the plasma profiles and magnetic geometry lead to intrinsic microturbulence above marginal stability for both ITG/TEM and ETG modes. However, neutral beam heating drives strong plasma rotation. The resulting $\boldsymbol{E} \boldsymbol{x} \boldsymbol{B}$ shearing rates (Fig. 1) are calculated with TRANSP. If we require (2-3) $\square_{T G}<\square_{\boldsymbol{E} \boldsymbol{x} \boldsymbol{B}}$ for stability, NSTX is near marginal stability for ITG at $0.8 \mathrm{r} / \mathrm{a}$. $\square_{T G}>2 \square_{E x \boldsymbol{B}}$ but it is not yet known if $\square_{E x \boldsymbol{B}}$ stabilizes ETG or microtearing modes.

Low $\square_{\mathrm{i}}$ and high $\square_{\mathrm{e}}$ in NSTX \#108730 could be understood to arise from stable ITG and unstable ETG and microtearing modes. With reversed shear, no unstable modes are found in the core, but if magnetic shear is not reversed ETG may be unstable there. $\boldsymbol{E x \boldsymbol { B }}$ shear is too weak to definitely stabilize ITG and lead to low $\square_{i}$. Resolution of this may be found by including better impurity data with GS2 and/or $\square^{*}$ stabilization effects, to be examined with GYRO. Nonlinear simulations are in progress.

\section{CMOD Gyrokinetic Simulations}

GS2 simulations of CMOD are focussed at the internal transport barrier (ITB) trigger time, just before a steep density profile is established. Linear calculations showed stable long wavelength turbulence at the ITB region, without invoking suppression by $\boldsymbol{E} \square \boldsymbol{B}$ shear[8]. Nonlinear simulation of the CMOD plasma shows quiescent microturbulence in the ITG range of frequencies in the barrier region, just before ITB formation (Fig. 3). These nonlinear calculations are electrostatic, rather than electromagnetic, which makes little difference in low $\square$, linear gyrokinetic simulations for CMOD. The simulations use four values of $k_{\square}$ and 23 values of $k_{r}$. In the plasma core, weak turbulence is predicted, with saturation occurring with the development of a Geodesic Acoustic Mode (GAM) (Fig. 3) at $77 \mathrm{kHz}$. A high frequency core mode at $80 \mathrm{kHz}$ for a similar experiment has been found with ECE[9]. The simulation mode is a stable mode of the plasma, excited as a damped computational mode, and which may be driven unstable by RF heating. The only well resolved linearly unstable mode is an ITG mode at about $50 \mathrm{kHz}$, outside the ITB region.

Identification of the driving forces responsible for drift wave microstability in the barrier region before the ITB appears, has been explored by examining the effects of increased gradients for the electron, ion, impurity density and temperatures as well as magnetic shear. It is found that increases in the normalized electron temperature gradient cause the largest destabilization of the ITG mode in the barrier region at the trigger time. This suggests that the ITB is triggered by reduction in the normalized electron temperature 
gradient driving force for the ITG/TEM microstability when off-axis RF heats the plasma locally. Reduced instability growth rates predicted at the barrier are consistent with the observed reduced transport[10]. GYRO simulations are found in good qualitative agreement with GS2 for the CMOD case, for linear, flux-tube, electromagnetic simulations including kinetic electrons but without impurities or noncircular magnetic geometry.

\section{Conclusions}

For the most part, gyrokinetic simulations of the NSTX and CMOD H-mode ITB experiments support the picture of unstable ITG(ETG) microturbulence driving high $\square_{i}\left(\square_{e}\right)$, and that suppressed ITG causes reduced particle transport and improved $\square_{\mathrm{i}}$. However, the present GS2 flux-tube microstability analysis disagrees with the above picture in two respects. At the NSTX edge, ITG may be unstable, yet transport analysis finds low $\square_{\mathrm{r}}[6]$. In addition, ETG is stable in the core, but high $\square_{\mathrm{e}}$ is observed[6]. We have identified a long anticipated, microturbulent mode with tearing parity on NSTX in the ITG-TEM range of frequencies. The mode is driven by electron dynamics and, along with ETG, may cause high $\square_{e}$. Nonlinear calculations for CMOD confirm initial linear simulations, which predicted ITG drift mode stability in the barrier region just before ITB formation. Future experiments on both devices will include MSE measurements of $q(r)$ as well as fluctuation data, to refine predictions for microturbulence.

\section{Acknowledgement}

We are glad to acknowledge the experimental and diagnostic teams at NSTX and Alcator C-MOD which provided the data and basis for the analysis in this paper. Research supported by U. S. DOE Contract DE-AC02-76CH03073.

[1] M. Kotschenreuther, et al., Comp. Phys. Comm. 88, 128 (1995).

[2] W. Dorland, et. al., Phys. Rev. Lett. 85, 5579 (2000).

[3] J. Candy, R. E. Waltz, J. Comput. Phys. 186 (2003) 545.

[4] D. Gates, et al. Phys. Plas.10, 1659 (2003).

[5] C. L. Fiore, et al. Phys. Plas. 8, 2023 (2001).

[6] B. LeBlanc, et al, this conference and submitted to Nuclear Fusion (2003).

[7] B. G. Hong, W. Horton, Phys. Fluids B1, 2527 (1989).

[8] M. H. Redi, et al., Proceedings EPS (2002), Montreux, Switzerland, Paper 1.082.

[9] A. Lynn, et al. IAEA H-mode Workshop, San Diego, CA (to be published 2003).

[10] S. Wukitch, et al., Phys. Plas. 9, 2149 (2002). 

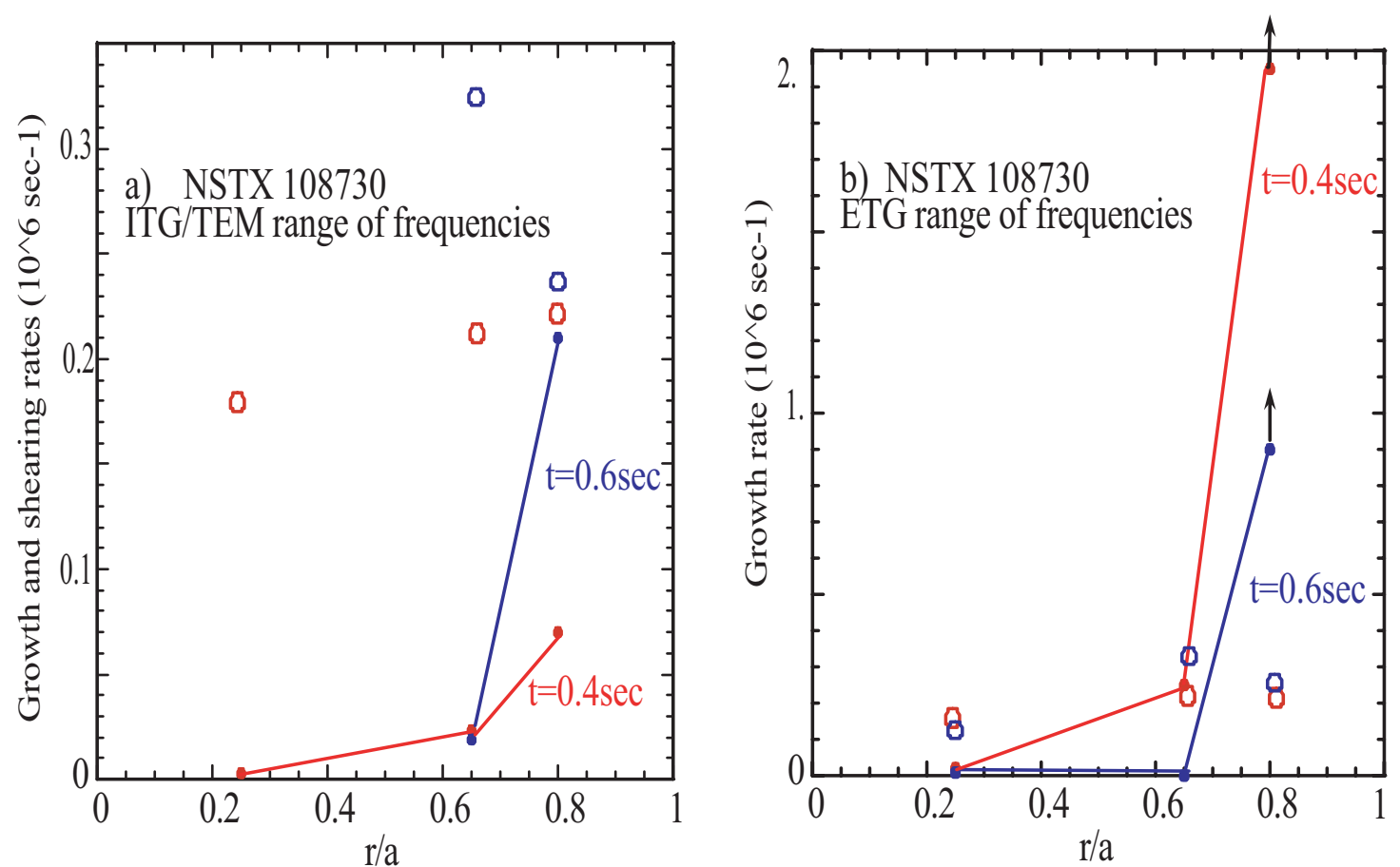

Fig. 1 Growth rates in the ITG/TEM (a) and ETG (b) range of wavelengths for the fastest growing mode at 0.4 seconds and 0.6 seconds in NSTX H-mode, at $0.25 \mathrm{r} / \mathrm{a}, 0.65 \mathrm{r} / \mathrm{a}$ and $0.8 \mathrm{r} / \mathrm{a}$. The open circles denote the ExB shearing rate. The ITG are intrinsically stable or are stabilized by shearing except possibly near the plasma edge, at $r / a=0.8$. ETG modes are stable in the core and not stabilized by shearing at 0.8r/a. Microtearing parity eigenfunction identified at $0.65 \mathrm{r} / \mathrm{a}$ in the ITG/TEM range of wavelengths.

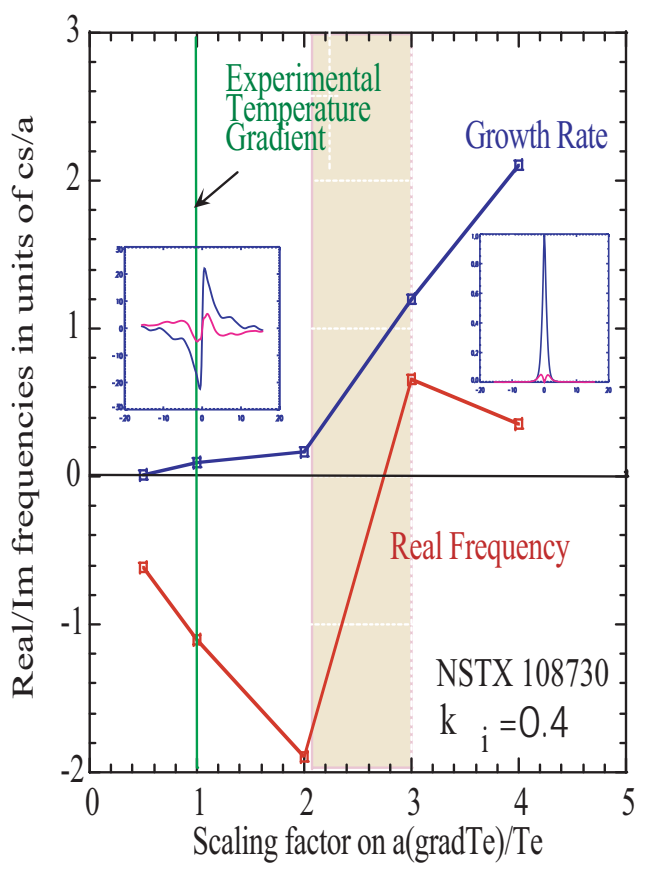

Fig. 2 At 0.65 r/a in the ITG/TEM range of wavelengths a microtearing instability is found, driven by electron temperature gradient. If all other gradients $=0$, mode structure is unchanged and growth rate decreases by $10 \%$. Without collisions or with increased electron temperature gradient, fastest growing mode is ITG. Insets: microtearing, ITG electrostatic eigenfunctions.

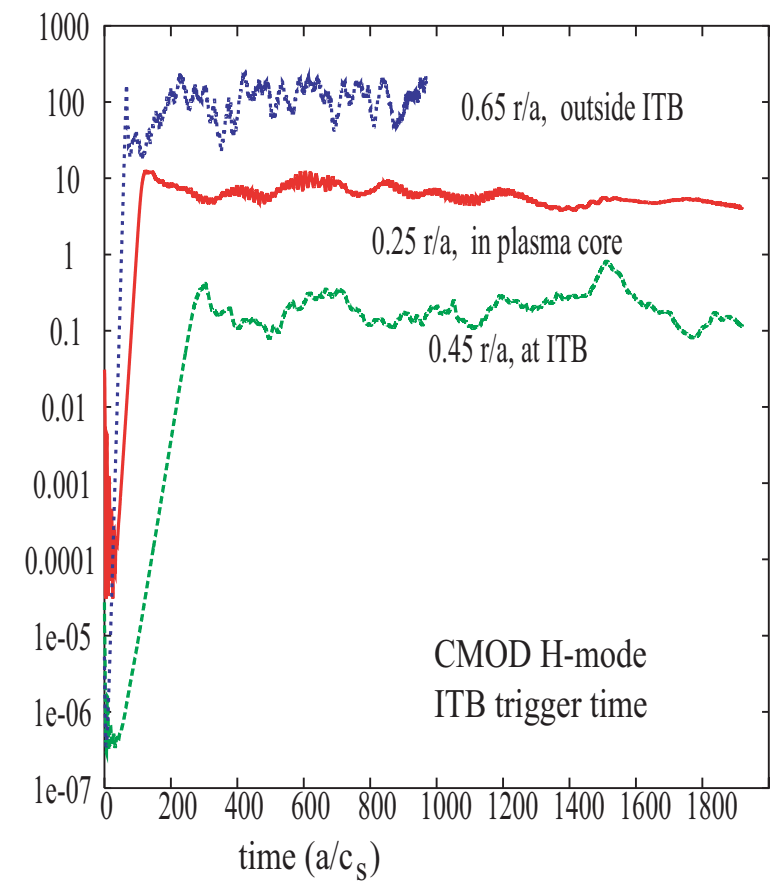

Fig. 3 Nonlinear, electrostatic simulations of CMOD before the ITB show the linear phase, followed by saturation. At the ITB region, the volume-integrated magnitude of the square of the fluctuation potential is reduced by two orders of magnitude, and by one order of magnitude in the plasma core, compared to the ITG unstable region outside the plasma core. A GAM mode develops in the plasma core. 


\section{External Distribution}

Plasma Research Laboratory, Australian National University, Australia

Professor I.R. Jones, Flinders University, Australia

Professor João Canalle, Instituto de Fisica DEQ/IF - UERJ, Brazil

Mr. Gerson O. Ludwig, Instituto Nacional de Pesquisas, Brazil

Dr. P.H. Sakanaka, Instituto Fisica, Brazil

The Librarian, Culham Laboratory, England

Mrs. S.A. Hutchinson, JET Library, England

Professor M.N. Bussac, Ecole Polytechnique, France

Librarian, Max-Planck-Institut für Plasmaphysik, Germany

Jolan Moldvai, Reports Library, Hungarian Academy of Sciences, Central Research Institute for Physics, Hungary

Dr. P. Kaw, Institute for Plasma Research, India

Ms. P.J. Pathak, Librarian, Institute for Plasma Research, India

Ms. Clelia De Palo, Associazione EURATOM-ENEA, Italy

Dr. G. Grosso, Instituto di Fisica del Plasma, Italy

Librarian, Naka Fusion Research Establishment, JAERI, Japan

Library, Laboratory for Complex Energy Processes, Institute for Advanced Study, Kyoto University, Japan

Research Information Center, National Institute for Fusion Science, Japan

Dr. O. Mitarai, Kyushu Tokai University, Japan

Dr. Jiangang Li, Institute of Plasma Physics, Chinese Academy of Sciences, People's Republic of China

Professor Yuping Huo, School of Physical Science and Technology, People's Republic of China

Library, Academia Sinica, Institute of Plasma Physics, People's Republic of China

Librarian, Institute of Physics, Chinese Academy of Sciences, People's Republic of China

Dr. S. Mirnov, TRINITI, Troitsk, Russian Federation, Russia

Dr. V.S. Strelkov, Kurchatov Institute, Russian Federation, Russia

Professor Peter Lukac, Katedra Fyziky Plazmy MFF UK, Mlynska dolina F-2, Komenskeho Univerzita, SK-842 15 Bratislava, Slovakia

Dr. G.S. Lee, Korea Basic Science Institute, South Korea

Institute for Plasma Research, University of Maryland, USA

Librarian, Fusion Energy Division, Oak Ridge National Laboratory, USA

Librarian, Institute of Fusion Studies, University of Texas, USA

Librarian, Magnetic Fusion Program, Lawrence Livermore National Laboratory, USA

Library, General Atomics, USA

Plasma Physics Group, Fusion Energy Research Program, University of California at San Diego, USA

Plasma Physics Library, Columbia University, USA

Alkesh Punjabi, Center for Fusion Research and Training, Hampton University, USA

Dr. W.M. Stacey, Fusion Research Center, Georgia Institute of Technology, USA

Dr. John Willis, U.S. Department of Energy, Office of Fusion Energy Sciences, USA

Mr. Paul H. Wright, Indianapolis, Indiana, USA 
The Princeton Plasma Physics Laboratory is operated by Princeton University under contract with the U.S. Department of Energy.

\author{
Information Services \\ Princeton Plasma Physics Laboratory \\ P.O. Box 451 \\ Princeton, NJ 08543
}

Phone: 609-243-2750

Fax: 609-243-2751

e-mail: pppl_info@pppl.gov

Internet Address: http://www.pppl.gov 